\title{
Use of Plasma Prealbumin concentration in assessment of nutritional status of adult patients admitted in rural Hospitals in Rivers State, Nigeria
}

\author{
*Orluwene Chituru Godwill;*Nkoyo Ntuen. \\ B.Med. Sci; MBBS; FMCPath.MBBS, FMCPath \\ * Department of Chemical Pathology, University of Port Harcourt Teaching Hospital, Port Harcourt, Nigeria
}

\begin{abstract}
Protein-energy malnutrition (PEM) is a common condition among patients admitted to hospitals, and it is associated with a worse prognosis and increased mortality. Although several screening systems are now available, PEM is still poorly recognized especially in the rural settings as there is no consensus on which test is more reliable and feasible in clinical practice. Prealbumin (PAB) is a potential useful PEM marker because its serum concentrations are closely related to early changes in nutritional status.

We studied PEM prevalence and PAB serum concentrations in 120 hospitalized patients. The Detailed Nutritional Assessment (DNA) was used as the reference method to determine PEM. PAB performance was compared with that of 2 other methods, the Subjective Global Assessment (SGA) and the Prognostic Inflammatory and Nutritional Index score (PINI).

According to the DNA reference method, $51 \%$ of patients were classified with mild malnutrition and $23 \%$ with severe malnutrition. PAB showed the best concordance with the standard DNA method (concordance index, 80\%) and a good sensitivity/specificity profile (84.9\%/78.9\%) compared with SGA and PINI.

We conclude that $P A B$ could represent a feasible and reliable tool in the evaluation of nutritionalstatus, especially in rural settings where it is difficult to obtain a more detailed and comprehensive nutritional assessment such as the DNA.
\end{abstract}

Keywords: Protein-energy Malnutrition, Prealbumin, Admitted-adult-patients, rural-hospitals, Rivers State.

\section{Introduction}

Protein-energy malnutrition (PEM) is a chronic or acute lean body protein loss that leads to a state of specific nutrient deficiency that produces a measureable change in body function. PEM is associated with a worse outcome during illness and may be reversed by conversion to an anabolic state. PEM is common in hospitalized patients and is associated with increased mortality [1,2]; 30-60\% of patients hospitalized for acute illness are malnourished, and nutritional status has been shown to deteriorate during hospitalization [3]. Reasons for this high prevalence include poor recognition and monitoring of nutritional status and inadequate intake of nutrients during hospitalization [4]. Malnutrition is also a major problem among residents in long-term care facilities. Furthermore, patients admitted to the hospital may already be malnourished or at risk of malnutrition. For many diseases, implementation of validated procedures for the early identification of malnourished patients is important for improving treatment response.

Anthropometric measurement (e.g. of triceps skin-fold thickness or arm-muscle circumference), an early method of nutritional assessment, has been shown to be an inaccurate indicator of nutritional status [2]. Several tools to assess malnutrition have been subsequently developed, many based on subjective evaluation from the operator, such as the Subjective Global Assessment (SGA) [5,6]. This method is based on the assessment of conditions associated with risk of malnutrition and on a physical examination that includes relevant features such as weight loss and loss of subcutaneous fat. A patient generated SGA is an alternative tool that includes data provided by the patient [7]. The Mini Nutritional assessment has been developed specifically for geriatric patients. Like the SGA, it includes evaluation of risk factors associated with malnutrition and additional information on nutritional habits [8].

The use of subjective assessment is very skill dependent and can result in underestimation of malnutrition risk. Alternative methods are based on the evaluation of individual biochemical variables, such as measurement of prealbumin (PAB) [9-11] or retinol binding protein (RBP) [12], or of multiple variables, as in the Prognostic Inflammatory and Nutritional Index (PINI) score [13], which includes evaluation of albumin, $\propto 1$ acid glycoprotein, and C-reactive peptide (CRP). Other tools, such as the Detailed Nutritional Assessment (DNA) [14], are based on the combination of both approaches and include history, physical examination, and biochemical data. An international consensus on a reference method is yet to be established. The DNA can be considered one of the most comprehensive methods, but it is time-consuming, costly, skill dependent, and unsuitable for large scale use. Therefore, there is a need for a method that is easy to use inclinical practice and 
especially in rural settings with adequate specificity and sensitivity to assess nutritional status in hospitalized patients.

Prealbumin has been shown to be a useful marker in monitoring malnourished patients as its serum concentrations are closely related to early changes in the nutritional status and it changes in response to nutritional support [11, 15-17]. We tested the feasibility, sensitivity and specificity of selected screening methods, namely SGA, PINI, PAB and RBP, compared with DNA, which we used in this study as a reference method.

\section{Subjects and methods}

We enrolled 120 patients (50 males and 70 females) admitted to 15 rural hospitals in Rivers State from February to May, 2006. Patients age ranged from 25 to 95 years (mean, 65 years). The study included patients admitted to general hospitals and government owned cottage hospitals in the rural communities of Rivers State. In all the cases, admission was for conditions that did not require surgery. Patient's characteristics are summarized in Table 1. The study protocol was approved by the Local Government Council Review Board in the affected Local Government Areas of theState and the management of the hospitals involved.Informed consent was obtained from all participants. All nutritional assessments and biochemical testing were performed on the $4^{\text {th }}$ day after admission as follows:

Detailed Nutritional Assessment (DNA) included chart review for height and weight, unintentional weight changes over the previous 3 months, total lymphocyte count, serum albumin concentration, total cholesterol concentration, body mass index, energy requirements and intake during a 24-hour period, and the presence of risk factors for malnutrition. Energy intakes were obtained by use of nutritional records of caloric intakes completed during the first 3 days of the hospital stay. The records were completed by the patientwith the assistance of caregivers. Nutritional needs were calculated with the Harris-Benedict formula corrected for activity and stress factor. Each criterion was scored as described by Azad et al [14], leading to 3 categories of patients: normal (score 7-11), mild malnutrition (score 12-15), and severe malnutrition (score $>15$ ).

Subjective GlobalAssessment (SGA) was based on the patient's history and physical examination. The clinical features addressed in the history were weight loss in the previous 6 months and the presence or absence of gastrointestinal symptoms such as anorexia, nausea, vomiting and diarrhoea. The physical examination included subjective assessment of the loss of subcutaneous fat over the triceps and midaxillary line of the lateral chest wall, muscle wasting in the deltoids and quadriceps, and the presence of ankle oedema and/or ascites. According to established criteria [5,6] patients were classified as class A (normal), class B (mild malnutrition), or class $\mathrm{C}$ (severe malnutrition).

Prealbumin (PAB) and Retinol Binding Protein (RBP) were assessed in accordance with previously proposed criteria [15]. Patients were classified in 3 categories: normal, with PAB serum concentrations> $0.17 \mathrm{~g} / \mathrm{L}$; mild malnutrition, with concentrations of $0.10-0.17 \mathrm{~g} / \mathrm{L}$; and severe malnutrition, with concentrations $<0.10 \mathrm{~g} / \mathrm{L}$. The RBP, cutoff values were as follows: normal, with RBP concentrations $>0.03 \mathrm{~g} / \mathrm{L}$; mild malnutrition, with concentrations of $0.02-0.03 \mathrm{~g} / \mathrm{L}$; and severe malnutrition, with concentrations $<0.02 \mathrm{~g} / \mathrm{L}$ (modified from Ingenbleek et al [12].

For Prognostic Inflammatory and Nutritional Index (PINI) scoring, we based on the measurement of the plasma concentrations of albumin, $\propto 1$-acid glycoprotein, and $\mathrm{C}$ - reactive protein $(\mathrm{CRP})$. We reduced the original 5-category classification [13] to 3 categories: normal (PINI score $<1$ ), mild malnutrition (PINI score 120 ), and severe malnutrition (those originally classified as "risk for death"; PINI score $>20$ ).

Laboratory measurements of PAB, RBP, and albumin were by nephelometric assay (BNII, Laser Nephelometer, Dade Behring). Total cholesterol was measured by the automated cholesterol oxidase: Paminophenazone (CHOD-PAP) method, CRP and $\propto 1$-acid glycoprotein by turbidimetric methods (Modular PP, Roche), and lymphocyte counts by ADVIA 120 (Bayer). All procedures were in accordance with quality service standards.

\section{Statistical Methods}

We used current criteria for the assessment of diagnostic tests, including concordance, sensitivity, and specificity, to evaluate the validity of methods used as alternatives to the DNA method, which served as the reference or gold standard. Agreement between DNA and the other nutritional assessments was also assessed with the Cohen (к) test, designed to measure the interrater agreement. Cohen (к) agreement was defined as "poor" ifк was $\leq 0.20$, "fair" if $\kappa$ was $>0.20$ and $\leq 0.60$, "substantial" if $\kappa$ as $>0.60$ and $\leq 0.80$, and "good" if Kwas > $0.80[18]$.

\section{Results}

Patients characteristics are shown in Table 1 and the nutritional laboratory parameters of the 120 patients used for this study are summarized in Table 2. For each method, percentages of patients in each 
category were as follows: DNA, 51\% mild malnutrition and 23\% severe malnutrition; SGA, 47\% mild malnutrition and $18 \%$ severe malnutrition; PINI, $45 \%$ mild malnutrition and $33 \%$ severe malnutrition; PAB, $50 \%$ mild malnutrition and 20\% severe malnutrition (Table 3). Given the highly significant correlation between $\mathrm{PAB}$ and $\mathrm{RBP}(\mathrm{r}=0.79 ; \mathrm{P}<0.001)$, and also taking into account the potential influence of chronic renal failures on $\mathrm{RBP}[12,15]$, we decided to use only PAB in the nutritional evaluation.

Prealbumin (PAB) showed the best concordance with the DNA reference method (concordance index, $80 \%$ ). Corresponding values for SGA and PINI were 64\% and 65\% respectively. Cohen test $\kappa$ values were 0.68 for PAB (indicating a strong agreement), 0.44 for PINI (fair agreement) and 0.41 for SGA (fair agreement).

After combining mild and severe malnutrition into a simple group, we evaluated the degree of sensitivity and specificity of different methods. Results for sensitivity/specificity with DNA as the reference methods were as follows: SGA, 75.1\%/81.4\%; PINI, 80.2\%/63.7\%; and PAB, 84.9\%/78.9\%. All methods showed good sensitivity. PAB showed the best sensitivity (84.9\%), and SGA showed the best specificity $(81.4 \%)$. PINI showed intermediate results, with good sensitivity and relatively poor specificity.

We found that only $21 \%$ of patients achieved at least $80 \%$ of their calculated nutritional need. However, we found no significant difference between DNA and PAB for patients reaching versus not reaching $80 \%$ of their required energy intake.Similarly, after stratification of malnourished and normally nourished patients, we observed no differences in mean PAB values when we compared patients above and below their $80 \%$ energy intake.

C-reactive protein (CRP)plasma concentrations were increased in 83 patients $(69 \%)$. We found a statisticallysignificant inverse correlation between PAB and CRP $(\mathrm{P}<0.05)$. Inspiteof the inverse relationship between PAB and CRP, we observed very good concordance between PAB and DNA at high and low CRP concentrations (Table 4), with concordance indexes of $80.6 \%$ and $78.0 \%$ for high and low CRP concentrations respectively.

\section{Discussion}

Protein energy malnutrition is a clinical condition characterized by depletion of muscle/body fat and visceral proteins and associated with increased morbidity and mortality. Protein energy malnutrition (PEM) in hospitalized patients has been traditionally considered a relatively rare condition affecting mainly the elderly and patients with severechronic diseases, cancer or protracted nutrients losses. Several studies have shown that malnutrition affects $30 \%-60 \%$ ofhospitalized patients $[2,3,19]$. Hypercatabolic states associated with acute or chronic disorders are important PEM determinants. On the other hand, a decreased food intake can be due to lack of assistance during meals, deglutition disorders, food withdrawal while waiting for radiologic or endoscopic investigations, mental confusion, and feeding refusal. Failure to identify these nutritional risk factors in patients early during the hospital stay can lead to health deterioration and increased length of stay, with associated costs [19-21].

Detailed nutritional assessment (DNA) can be considered a reliable procedure to identify patients at risk of malnutrition, but this method is time-consuming and difficult to use on a large scale. In the last few years, many nutritional screening tools have been developed, tested and implemented inclinical practice, several combining laboratory tests and patient information [22]. Biochemical markers have always been an attractive option because they are easier to introduce and standardize in clinical practice. Albumin is a traditional marker of nutritional status, but its large body pool, with a half-life of 20 days, and its sensitivity to the patients hydration state make it too sensitive to be used to assess PEM. Prealbumin (PAB) is a better nutritional marker because it has a short half-life (48hours), a relatively small body pool, and a rapid rate of synthesis that responds to protein intake [9]. Plasma PAB concentration has been shown to significantly decrease only 3 days after inadequate nutrient intake [16], and to increase $1 \mathrm{mg} /$ day when the nutrient needs are satisfied [17]; plasma PAB can be influenced by an acute or chronic renal insufficiency [16].

Our prevalence data, which showed that $74 \%$ of patients had variable degrees of malnutrition (Table 3 ), are in agreement with the literature [1-3] even though our own percentage is a little higher because of the rural environment (in a developing country) of our study. The higher percentage of patients with severe malnutrition identified with PINI can be explained by the fact that this method is affected by plasma concentrations of acute-phase proteins indicative of a stress hypermetabolic response. In our study group, only 25 patients $(21 \%)$ achieved at least $80 \%$ of their calculated nutritional need, a cutoff value that has been shown to correlate with a high risk of malnutrition during hospitalization [23].

Our results showed various degrees of concordance between DNA and the alternative methods investigated. Among these, PAB showed the best concordance with DNA and a good sensitivity/specificity profile. A major limitation to the use of biochemical markers is that their plasma concentrations may be influenced by pathogenic conditions. In particular, PAB concentrations decrease in the presence of inflammation (negative acute-phase reactant). The inverse correlation between PAB and CRP concentrations may represent a confounding factor in the interpretation of the results. Plasma PAB concentrations change rapidly; a decrease of 
up to 50\% in PAB concentration is expected after few days of inadequate nutrient intake and/or diseases with an acute phase response, conditions that often coexist in severely ill patients [24]. Conversely a rapid increase of $\mathrm{PAB}$ concentration is seen when adequate nutritional intake is restored [21] or CRP stabilizes [25]; therefore rapid changes in CRP can induce an overestimation of malnutrition. Although these limitations should be taken into consideration, our data suggests that PAB can still be reliable in cases involving inflammation. A good correlation between PAB and DNA was found at both high and low CRP concentrations (Table 4). Notably, CRP and other markers of acute-phase response are not included in the DNA score calculation.

\section{Conclusion}

Our study results indicate that $\mathrm{PAB}$ is an inexpensive, feasible, and reliable tool in the evaluation of malnutrition affecting hospitalized patients, particularly in rural settings in the developing countries where it is difficult to perform a more detailed and comprehensive nutritional assessment such as DNA. Further investigation with sequentialmeasurements is needed to elucidate the complex relationship between $\mathrm{PAB}$ and inflammation and clarify the role of PAB in monitoring the efficacy of nutritional interventions.

\begin{tabular}{|c|c|c|c|}
\hline & Number & & $\%$ \\
\hline Age, mean (Range) & $65(25-95)$ & & \\
\hline \multicolumn{4}{|l|}{ Sex } \\
\hline Female & 70 & & 58 \\
\hline Males & 50 & & 42 \\
\hline \multicolumn{4}{|l|}{ Clinical Condition* } \\
\hline Diabetes & 40 & & 33 \\
\hline Cerebrovascular accident (Stroke) & 20 & & 17 \\
\hline Cancer & 18 & & 15 \\
\hline Congestive heart failure & 34 & & 28 \\
\hline Infection & 30 & & 25 \\
\hline Trauma & 21 & & 18 \\
\hline$\geq 2$ conditions & 58 & & 48 \\
\hline \multicolumn{4}{|l|}{ Nutritional Variables } \\
\hline$>5 \%$ unintentional weight loss over 3 months & 41 & & 34 \\
\hline$\geq 80 \%$ energy need intake & 25 & & 21 \\
\hline \multicolumn{4}{|l|}{ Laboratory Values } \\
\hline Albumin $<2.8 \mathrm{~g} / \mathrm{L}$ & 40 & & 33 \\
\hline Cholesterol $<4.7 \mathrm{mmol} / \mathrm{L}$ & 48 & & 40 \\
\hline Lymphocyte count $<1200 /$ fl & 38 & & 32 \\
\hline C-reactive protein $>5 \mathrm{mg} / \mathrm{L}$ & & 69 & \\
\hline \multicolumn{4}{|l|}{ Note: } \\
\hline * Patients may be affected by more than one dis & & & \\
\hline
\end{tabular}




\begin{tabular}{|lcc|}
\hline \multicolumn{2}{|c|}{ Table 2: Patients Laboratory and Nutritional values } \\
\hline & Range & Mean (SD) \\
Body mass index, $\mathrm{kg} / \mathrm{m}^{2}$ & $11.0-42.2$ & $23.7(4.7)$ \\
Albumin, $\mathrm{g} / \mathrm{L}$ & $1.3-4.9$ & $3.3(0.8)$ \\
Prealbumin, $\mathrm{g} / \mathrm{L}$ & $0.01-0.35$ & $0.14(0.04)$ \\
C - reactive protein, $\mathrm{mg} / \mathrm{L}$ & $0.2-250.0$ & $37.5(45.0)$ \\
RBP, g/L & $0.01-0.09$ & $0.04(0.02)$ \\
$\propto 1$-Acid glycoprotein, $\mathrm{g} / \mathrm{L}$ & $0.17-2.72$ & $1.33(0.45)$ \\
24-hourcaloric needs, kcal & $1000-3000$ & $1095(398)$ \\
24-hour caloric intakes, kcal & $239-2350$ & $70.9(24.6)$ \\
Difference (decrease) of intake Vs needs, $\%$ & $17-180$ & \\
& & \\
\hline Note: & & \\
RBP: Retinol Binding Protein & & \\
& &
\end{tabular}

\begin{tabular}{|c|c|c|c|}
\hline \multicolumn{4}{|c|}{ Table 3:Prevalence of malnutrition assessed using different methods in 120 patients } \\
\hline \multicolumn{2}{|c|}{ Normal\% } & \multirow{2}{*}{$\begin{array}{l}\text { Mild malnutrition } \% \\
\qquad 51\end{array}$} & \multirow{2}{*}{$\begin{array}{c}\text { Severe malnutrition } \% \\
23\end{array}$} \\
\hline DNA (reference method for this study) & 26 & & \\
\hline SGA & 35 & 47 & 18 \\
\hline PINI & 22 & 45 & 33 \\
\hline PAB & 29 & 50 & 21 \\
\hline RBP & 26 & 54 & 20 \\
\hline \multicolumn{4}{|l|}{ Note: } \\
\hline \multicolumn{4}{|l|}{ Detailed Nutritional Assessment } \\
\hline \multicolumn{4}{|l|}{ Subjective Global Assessment } \\
\hline \multicolumn{4}{|c|}{ Prognostic Inflammatory and Nutritional Index score } \\
\hline \multicolumn{4}{|l|}{ Pre-albumin } \\
\hline \multicolumn{4}{|l|}{ Retinol Binding Protein } \\
\hline
\end{tabular}


Table 4: Prevalence of Malnutrition in 120 patients assessed by PAB and DNA at different concentrations of C - reactive protein (CRP)

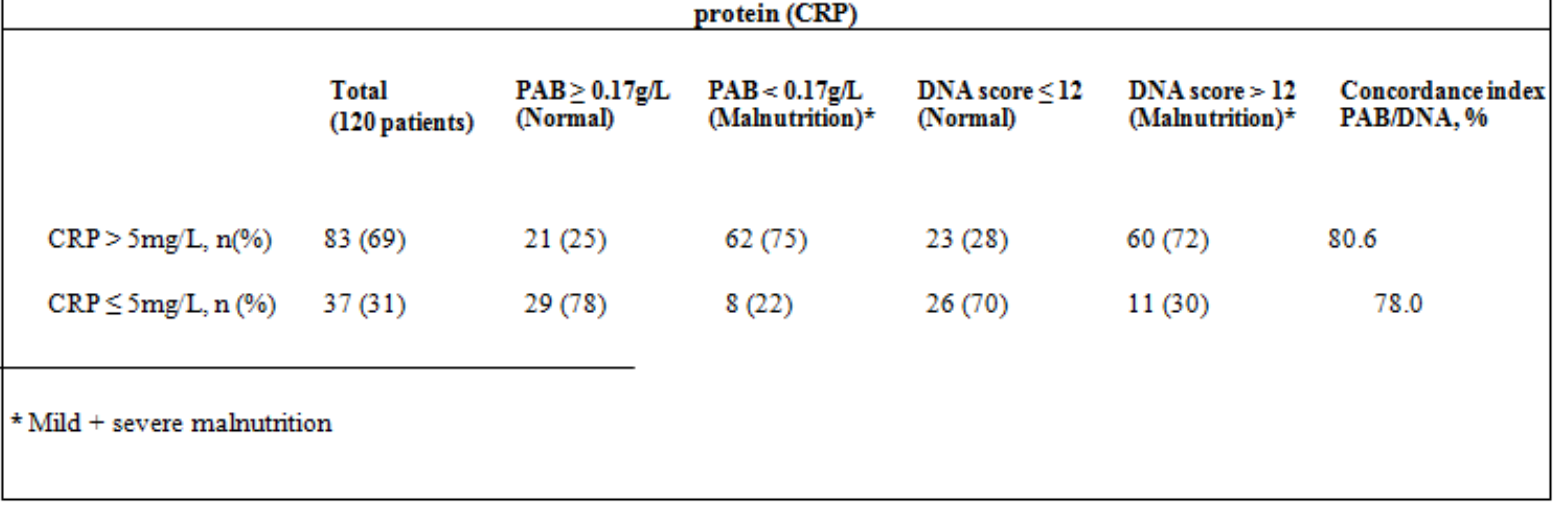

\section{References}

[1]. J. P. McWhirter, C. R. Pennington. Incidence and recognition of malnutrition in hospital. BMJ 308, $1994,945-948$.

[2]. B. R. Bistrian, G. L. Blakburn, J. Vitale, D. Cochran, J. Naylor. Prevalence of malnutrition in general medical patients. JAMA 235, 1976, 1567-1570.

[3]. R. Roubenoff, R. A. Roubenoff, J. Preto, C. W. Balke. Malnutrition among hospitalized patients. A problem of physician awareness. Arch Intern Med 147, 1987, 1462-1465.

[4]. K. G. Coats, S. L. Morgan, A. A. Bartolucci, R. L. Weinser. Hospital-associated malnutrition: a re-evaluation 12 years later. J Am Diet Assoc 93, 1993, 27-33.

[5] A. S. Detsky, J. R. McLaughlin, J. P. Baker, N. Johnston, S. Whittaker, R. A. Mendelson, et al. What is subjective global assessment of nutritional status? JPEN J Parenter Enteral Nutr 11, 1987, 8-13.

[6] J. P. Baker, A. S. Detsky, D. E. Wesson, S. L. Wolman, S. Stewart, J. Whitewell, et al. Nutritional assessment: a comparison of clinical judgement and objective measurements. N Engl J Med 306, 1982, 969-972.

[7] J. Martineau, J. D. Bauer, E. Isenring, S. Cohen. Malnutrition determined by the patient-generated subjective global assessment is associated with poor outcomes in acute stroke patients. Clin Nutr 24, 2005, 1073-1077.

[8] M. D. Persson, K. E. Brismar, K. S. Katzarski, J. Nordenstrom, T. E. Cederholm. Nutritional status using mini nutritional assessment and subjective global assessment predict mortality in geriatric patients. J Am Geriatr Soc 50, 2002 , $1996-2002$.

[9] E. Mears. Linking serum prealbumin measurements to managing a malnutrition clinical pathway. J Clin Ligand Assay 22, 1999, 296-303.

[10] Y. Ingenbleek, H. G. Van Den Schrieck, P. De Nayer, M. De Visscher. Albumin, transferrin and thyroxin-binding protein (TBPARBP) complex in assessment of malnutrition. Clin Chim Acta 63, 1975, 61-67.

[11] L. H. Bernstein, Y. Ingenbleek. Transthyretin: its response to malnutrition and stress injury. Clinical usefulness and economic implications. Clin Chem Lab Med 40, 2002, 1344-1348.

[12] Y. Ingenbleek, H. G. Van Den Schrieck, P. De Nayer, M. De Visscher. The role of retinol-binding protein in protein-calorie malnutrition. Metabolism 24, 1975-633-641.

[13] Y. Ingenbleek, Y. A. Carpentier. A prognostic inflammatory and nutritional index scoring of critically ill patients. Internat $J$ Vitam Nutr Res 55, 1984, 91-101.

[14] N. Azad, J. Murphy, S. Amos, J. Toppan. Nutrition survey in an elderly population following admission to a tertiary care hospital. CMAJ 161 (5), 1999, 511-515.

[15] A. M. Spiekerman. Proteins used in nutritional assessment (Review). Clin Lab Med 13 (2), 1993, 353 -369.

[16] L. H. Bernstein, W. Pleban. Preablumin in nutrition evaluation. Nutrition 12, 1996, 255-259.

[17] L. H. Bernstein, C. J. Lenkhardt-Fairfield, W. Pleban, R. Rudolph. Usefulness of data on albumin and prealbumin concentrations in determining effectiveness of nutritional support. Clin Chem 35, 1989, 271-274.

[18] J. R. Landis, G. G. Koch. The measurement of the observer agreement for categorical data. Biometrics 33, $1977,159-174$.

[19] J. J. Reilly, S. F. Hull, N. Albert, A. Waller, S. Bringardener. Economic impact of malnutrition: a model system for hospitalized patients. JPEN J Parenter Enteral Nutr 12, 1988, 371-376.

[20] L. H. Bernstein, T. A. Shaw-Stiffel, M. Schorrow, R. Brouillette. Financial implication of malnutrition. Clin Lab Med 13, 1993, 491-507.

[21] E. Mears. Outcomes of continuous process improvement of a nutritional care program incorporating TTR measurements. Clin Chem Lab Med 40, 2002, 1355-1359.

[22] L. Brugler, A. K. Stankovic, M. Schlefer, L. Bernstein. A simplified nutrition screen for hospitalized patients using readily available laboratory and patient information. Nutrition 21, 2005, 650-658.

[23] A. M. Spiekerman, R. A. Rudolph, L. H. Bernstein. Determination of malnutrition in hospitalized patients with the use ofa group based reference. Arch Pathol Lab Med 117, 1993, 184-187.

[24] P. S. Shetty, K. E. Watrasiewicz, R. T. Jung, W. P. James. Rapid-turnover transport proteins: an index of subclinical protein-energy malnutrition. Lancet 2, 1979, 230-232.

[25] M. A. Clark, B. T. Hentzen, L. D. Plank, G. I. Hill. Sequential changes in insulin-like growth factor 1, plasma proteins, and total body protein in severe sepsis and multiple injury. JPEN J Parenter Enteral Nutr 20, 1996, 363-370. 